\title{
Design of Augmented Reality for Collaboration
}

Susanna Nilsson, Björn Johansson and Arne Jönsson

The self-archived postprint version of this journal article is available at Linköping University Institutional Repository (DiVA):

http://urn.kb.se/resolve?urn=urn:nbn:se:liu:diva-4.3712

N.B.: When citing this work, cite the original publication.

Nilsson, S., Johansson, B., Jönsson, A., (2008), Design of Augmented Reality for Collaboration, Proceedings of The 7th ACM SIGGRAPH International Conference on Virtual-Reality Continuum and Its Applications in Industry, VRCAI 2008. https://doi.org/10.1145/1477862.1477920

Original publication available at:

https://doi.org/10.1145/1477862.1477920

Copyright: ACM

http://www.acm.org/

(C) ACM 2008. This is the author's version of the work. It is posted here for your personal use. Not for redistribution. 


\section{Design of Augmented Reality for Collaboration}

\author{
Susanna Nilsson* \\ Linköping University, Sweden
}

\author{
Björn Johansson ${ }^{\dagger}$ \\ Saab Security, Sweden.
}

\author{
Arne Jönsson $\ddagger$ \\ Santa Anna IT Research Institute AB
}

\begin{abstract}
Augmented Reality has potential to support collaboration in complex situations, such as command and control. Unfortunately there are few studies on how such systems should be designed to facilitate cooperation between actors from different organisations and at the same time support individual actors needs. This poster presents an iterative design process of an Augmented Reality system for a collaborative task.
\end{abstract}

Keywords: Human-centered design, collaborative work, Augmented Reality

\section{Introduction}

In complex collaborative situations, such as command and control in crisis management, actors from different domains and organisations must work together [Cross and Bopping 1998]. However, collaborative work across organisational borders is not simple and confusion emerging from differences in terminology is not rare. We believe that Augmented Reality (AR) is especially suitable to support collaboration between actors from different organisations. AR allows for independence and individuality [Billinghurst and Kato 2002] meaning that each actor can independently have data tailored to her needs in various situations. AR also supports cooperation [Billinghurst and Kato 2002] as the actors can see each other and cooperate in a natural way. This poster presents an iterative design of a multi-user AR application, where AR is used to aid cross-cultural collaboration. The system is intended to support collaborative work between representatives from police, rescue services and military personnel, working jointly with the goal of coordinating work in a crisis situation.

\section{Background and related work}

AR research has to a large extent been focused on single user applications with different purposes, such as applications that provide the user with instructions. Billinghurst \& Kato [2002] presented a vision of shared space using AR technology and since then several papers have illustrated different ideas of merging AR with collaborative computing

\footnotetext{
*e-mail: susni@ida.liu.se

$\dagger$ e-mail:bjorn.j.e.johansson@combitech.se

‡e-mail:arnjo@ida.liu.se
}

approaches. Even though AR systems are designed differently with different applications and tasks in focus the methods used to evaluate them are similar and mainly based on usability methods used for more traditional graphical user interfaces, sometimes in combination with usability for VR applications [Träskbäck 2004; Nilsson and Johansson 2006; Dünser et al. 2006]. This approach has some complications since it is not based on the experiences from actual AR systems users in actual contexts.

\section{Method}

We have adapted an iterative design approach where realistic exercises are combined with focus groups in an effort to catch both user behaviour and opinions. The design study included a pre-design phase where field experts from three different organisations (fire and rescue services, police department and the helicopter platoon in the local area) took part in a brainstorming session to establish the parameters of the AR system. This brainstorming session was used to define the components of the software interface and based on an analysis of the brainstorming session a first design was implemented.

\section{The first design}

In this section we describe the first AR system prototype as well as the setting of the study and the results of the evaluation. Observations, focus groups and questionnaires were the main tools for collecting data. The task for the participants was to collaborate in responding to a forest fire. The AR system was used as a tool for them to see and manipulate their resources and as a way to have an overall view of the situation, while cooperating over a digital map.

\subsection{System description}

The AR-system used hand-held devices that are easier to remove than head mounted displays. We used a digital map were participants had personal, individual views, allowing them to see an organisation specific map and the symbols they normally use. In this way each actor has her own information mapping to the AR markers on the map to facilitate independence and individuality. Hand pointing on the digital map was not possible and instead an interaction device to point digitally was used.

\subsection{Results}

The first evaluation revealed a number of issues regarding the design of the system as well as the scenario used. In general, the participants were positive to the AR system. What they appreciated most was the easy overview of what was going on, being able to see all resources placed on the map facilitates the joint task. The design of the AR system as a handheld device did not receive a positive response and the observations clearly illustrated this point. Despite this the participants thought it was easy to use and that it was quick to learn. 


\section{The second design}

The follow-up study was conducted as a focus group where the participants were asked to reflect on their experience in the first study. Then the redesigned system was presented and the participants were observed using it to complete simple tasks from the scenario in the prevoius study. After this the focus group discussion continued with reflection on the new design.

\subsection{System description - the new design}

The handheld display was replaced with a head mounted display allowing freedom of movement, Figure 1. The interaction device was also considerably redesigned and in the new AR system the user can easily manipulate objects using only one hand as opposed to using both in the previous prototype, see insert in Figure 1.

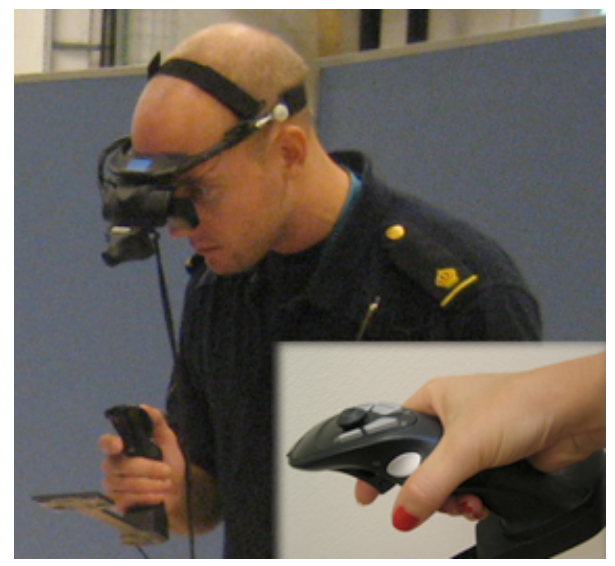

Figure 1: The redesigned display and interaction device, which allows the user to choose a virtual object and place it on the digital map.

Another improvement made was a simplified interaction in where the user can point at things in the digital map, see Figure 2.

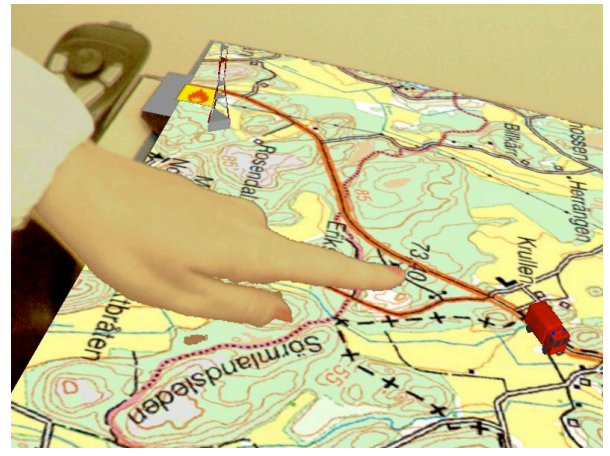

Figure 2: Deictic pointing in a digital map as seen through the head mounted display of the re-designed AR system.

\subsection{Results}

The head mounted display was a big improvement and allowed the users to move around and interact more freely.
The new interaction device was also appreciated and the participants found it very easy to use and quick to learn. The added possibility to see hand gestures such as pointing, on the digital map has simplified the interaction considerably and also results in a more natural interaction and better communication between the participants. The participants did not only appreciate the new design, it also gave them ideas on how to further use the AR system and see the potential of future applications, such as in distributed collaborative tasks.

\section{Discussion and implications}

We have presented an iterative design process of AR devices for collaboration. The AR system was developed in several steps in studies with real users, in near real settings. As a result of our investigations the design of the AR system was greatly improved during the iterations and we are now ready to conduct full scale studies of the use of AR for collaboration in crisis management. Working iteratively with re-design and evaluation, involving real users is invaluable. Making only one major evaluation, as often is the case in AR studies, obscures both flaws and opportunities with new technology. The design described in this paper is not yet final, and the real challenge sets in during the next phase - when our AR system is to be tested in an extensive naturalistic study with participants from the field.

\section{Acknowledgements}

This research is supported by FMV, Technology for Sweden's Security. We are indebted to XMReality for developing the system used in the studies and to Fredrik Köhler who assisted in the studies, and of course to our participants who volunteered their time and effort to this project.

\section{References}

Billinghurst, M., And Kato, H. 2002. Collaborative augmented reality. Communications of the ACM 45, 7 (July), 64-70

Cross, M., And Bopping, C. 1998. Collaborative planning processes in command and control. In Fourth International in Command and Control Research and Technology, DoD CCRP.

Dünser, A., Steinbügl, K., Kaufmann, H., And GlüCK, J. 2006. Virtual and augmented reality as spatial ability training tools. In Proceedings of the 7 th ACM SIGCHI New Zealand Chapter's International Conference on Computer-Human Interaction: Design Centered HCI, 2006, Christchurch, New Zealand, July 6-7, 2006, ACM, M. Billinghurst, Ed., vol. 158 of ACM International Conference Proceeding Series, 125-132.

Nilsson, S., And Johansson, B. 2006. A cognitive systems engineering perspective on the design of mixed reality systems. In ECCE '06: Proceedings of the 13th Eurpoean conference on Cognitive ergonomics, ACM, New York, NY, USA, 154-161.

TrÄskBÄCK, M. 2004. Toward a usable mixed reality authoring tool. In $V L / H C C$, IEEE Computer Society, 160162 . 